\title{
The Prevalence and Symptoms of Premenstrual Syndrome under Examination
}

\author{
Nasim Naeimi \\ Department of Biology, Faculty of Science, University of Sistan and Baluchestan, Zahedan, Iran \\ Email: nnaeimi@rocketmail.com, naeimi@science.usb.ac.ir
}

Received 30 November 2014; accepted 15 December 2014; published 16 January 2015

Copyright (C) 2015 by author and Scientific Research Publishing Inc.

This work is licensed under the Creative Commons Attribution International License (CC BY). http://creativecommons.org/licenses/by/4.0/

(c) (i) Open Access

\begin{abstract}
Introduction: Premenstrual Syndrome (PMS) is a common disorder in childbearing age. Based on different definitions, it is accompanied with specific annoying symptoms that clearly emerge after ovulation and decrease or end with the onset of menstruation. Methods: The present study aimed to determine the prevalence of premenstrual syndrome in university students of Sistan and Baluchestan University (Iran) in the academic year 2013-2014. Two hundred and one female university students living in dormitories were randomly selected. The subjects completed two questionnaires of Demographic Information and Symptom Assessment based on the criteria of ACOG and DSM-IV. Results: According to the mentioned criteria, "36.3\%" of subjects suffered from Premenstrual Dysphoric Disorder (PMDD) and "85.6\%" of subjects indicated the symptoms of PMS. The severity of PMS in 14(\%7) subjects was high. Of 86 and 72 subjects " $42.8 \%$ " and "35.8\%" was moderate respectively, it was mild. Among university students, the most common mood symptom (emotional) and somatic symptom (physical) were fatigue and lethargy and abdominal pain ("72.6\%" and "62.7\%", respectively). PMS was significantly related to dysmenorrhea and severity of menstrual pain $(p<0.05)$. Conclusion: Given the high prevalence of this syndrome and its effect on various aspects of life, we highly recommend informing young individuals through books, workshops and media in order to identify the symptoms, provide information about methods of control and treatment of this syndrome, and apply non-interventional treatments and methods to reduce the symptoms.
\end{abstract}

\section{Keywords}

Premenstrual Syndrome, Prevalence, Severity

\section{Introduction}

Nowadays, women's health is one of the main objectives of the health and is an indicator of social and economic

How to cite this paper: Naeimi, N. (2015) The Prevalence and Symptoms of Premenstrual Syndrome under Examination. Journal of Biosciences and Medicines, 3, 1-8. http://dx.doi.org/10.4236/jbm.2015.31001 
development. Most women may experience cyclical changes in their physical, mental and behavioral status during their childbearing years [1]. These changes may initiate from $12-6$ days prior to the menstruation cycle and lasted for 2 days (up to 4 days) after the onset of menstruation [2]. Before Christ, Hippocrates, for the first time, mentioned a series of physical and psychological changes in his writing [3]. In 1931, Robert Frank, an American physician in the New York Academy of Medicine, raised the issue and stated that it could be due to ovarian dysfunction and used the term luteal action or premenstrual tension for this phenomena. In the same year, a psychoanalysis named Karen Horney stated that this syndrome is the result of sexual desire and power [4] [5] and applied the term Premenstrual Syndrome (PMS) to describe it [6].

In mid 1980s, severe form of PMS was called Premenstrual Dysphoric Disorder (PMDD) [7]. Therefore, the premenstrual syndrome is a clinical condition associated with huge uncertainties in the etiology which includes a series of physical, cognitive, behavioral and mood changes that occur periodically in the luteal phase of the menstrual cycle and decrease or end with menstruation. Symptoms range is very broad and affects all aspects of life (family, social, occupational, etc.) [8]-[10]. The condition for PMS diagnosis is the existence of two consecutive periods accompanied with annoying changes [11] [12]. Hence, this syndrome is a broad concept with various severity that differs from one individual to another [13].

The cause of this syndrome is still unknown and several theories have been proposed to explain the case. However, there is no laboratory test for this syndrome and diagnosis is just conducted based on the diaries of individual's physical and psychological changes [14]. Previously conducted studies have identified more than 200 types of signs and symptoms of premenstrual syndrome which significantly affect individuals' quality of life [15] [16]. Menstrual disorders are very common among teenagers and young women. These disorders are often considered as sources of anxiety for patients and their families. Premenstrual dysphoric disorder focuses more on psychological factors, while the syndrome mostly accompanies with somatic symptoms [17].

Academic authorities have issued various criteria for PMS. 1) American College of Obstetrics and Gynecology (ACOG) mentioned that this syndrome is at least accompanied with an emotional or a physical symptom that occurs before menstruation and after its initiation, the symptoms may disappear without any pharmacological intervention [18] [19].

2) Diagnostic and Statistical Manual of Mental Disorder-IV (DSM-IV) which identifies PMDD and emphasizes on mood disorders stated that the existence of at least 5 symptoms out of 11 symptoms mentioned for this syndrome is essential [20]. These 11 symptoms are stress and anxiety, change of mood (feeling sad or crying all of a sudden), depressed mood, persistent anger or personal clashes, reduced interest in social relationships and work, feeling of immersion or being out of control, change in appetite (overeating or having little appetite), difficulty in sleeping (oversleeping or insomnia), lack of concentration, fatigue and lethargy, and physical symptoms (chest pain, abdominal pain, joint or muscle pain, frequent urination, weight gain, back pain, acne, nausea, abdominal bloating, chest pain and chest sensitivity, headache) [21] [22].

The exact prevalence of this syndrome is still unknown and it depends on many factors. This syndrome is one of the most controversial issues related to women [23]. A review study indicated that the prevalence of this syndrome is 14 - 88 percent among which 5 - 10 percent of women suffer from its severe type [24]. Due to the variety of symptoms, severity and type of diagnostic criteria, estimating the prevalence of this syndrome is hard and varies in each society. Some previously conducted studies reported that its prevalence is 20 - 90 percent [25].

In fact, about $90 \%$ of women have reported some of the symptoms of premenstrual syndrome in some of their cycles. Approximately, "20\%" of women have frequently experienced behavioral, emotional or physical symptoms of premenstrual syndrome in their childbearing age [26].

Various theories, including that those who are physiologically more sensitive to normal cyclical changes in estrogen and progesterone are prune to this syndrome, considering psychological, medical, social, nutritional causes and etc. which could have consequences for the individual and society, have been proposed for this syndrome [27]-[30].

Since in our country, little sporadic studies have been carried out on this issue and given the importance of the high prevalence and its serious consequences on patients' performance, the present study aimed to examine the frequency of this syndrome in university students living in dormitories of Sistan and Baluchestan University.

\section{Methods}

The statistical population of this descriptive study included all female university students living in dormitories of 
Sistan and Baluchestan University in the academic year 2013-2014. To this end, after obtaining the subjects' consent and emphasizing on the confidentiality of the information, questionnaires were completed by the subjects. Exclusion criteria were drug use (due to internal conditions including endocrine disorders, autoimmune diseases and gynecological diseases such as polycystic ovaries and endometriosis), panic disorder and periodicals, bipolar disorder, personal disorders and psychosis. Total sample of 207 individuals participated in the study. This is while 2 individuals were eliminated from the study due to their incomplete questionnaires and 4 other individuals were excluded due to other exclusion criteria (since these symptoms are similar to symptoms create by premenstrual syndrome or premenstrual dysphoric disorder). Finally, the sample size was 201 individuals.

Data were collected using two structured questionnaires:

1) Demographic and social information form including age, marital status, place of residence, history of pregnancy, menstrual status (dysmenorrhea, pain severity, and length of menstruation)

2) Symptom Assessment Questionnaire containing 20 self-reported questions which evaluate the frequency and severity of this syndrome, 10 questions related to psychological signs and 10 questions related to physical signs.

Reported criteria for diagnosis of PMS and DSM-IV signs were extracted from previously conducted studies and considered as a valid questionnaire [24].

The mentioned questionnaire was provided individually to participants. They were asked to fill out the demographic section (without mentioning their name) and report any symptoms they had experienced during the last month before their menstruation. In this study, instead of daily recorded symptoms based on standard tables, retrospective symptoms assessment method was used [31], (to avoid disappearance of the questionnaires or/and lack of precision and time in recording daily symptoms). Subjects were asked to determine the severity of PMS symptoms based on a 5 -point Likert scale $(0=$ not at all; $1=$ mild; 2 = moderate; 3 = relatively severe; 4 = severe).

To determine the prevalence of premenstrual syndrome, ACOG criteria for PMS which includes 2 symptoms (at least one emotional and one physical symptoms) with moderate and more than moderate severity were considered (those who reported mild symptoms were not regarded as patients) [32].

Considering those eleven symptoms mentioned earlier, subjects with at least 5 symptoms were diagnosed as individuals with premenstrual dysphoric disorder [33]. Reliability and validity of the questionnaire of premenstrual syndrome was evaluated based on ACOG and DSM-IV and its intensity scale (Likert) was confirmed for Iranian community [24] [34].

The obtained data were analyzed using SPSS 17.

To describe university students' characteristics, descriptive statistics method (frequencies and percentages) was applied and to examine the relationship between the dependent and independent variables, chi-square tests and logistic regression analysis (one-way ANOVA) were used. $\mathrm{P}<0.05$ was considered significant.

\section{Results}

The current study aimed to determine the prevalence and severity of premenstrual syndrome and the effecting factor on this syndrome in female university students living in dormitories of Sistan and Baluchestan University. 201 individuals completed the questionnaire. Investigating the obtained results from the first questionnaire, i.e., the Demographic Information, indicated the following results.

86 individuals " $42.8 \%$ ” were 18 - 20 years, 93 individuals “44.3\%” were 20 - 23 years and 22 individuals "10.9\%" were more than 24 years. Among these individuals, 166 "82.6\%" were single and 35 individuals "17.4\%" were married among whom 7 married individuals "3.5\%" had a history of pregnancy. Others 194 " $96.5 \%$ " had no such experience. 166 female students " $82.6 \%$ " were non-indigenous and 35 students " $17.4 \%$ " were indigenous. Most of these students, 166 individuals " $84.1 \%$ " have experienced dysmenorrhea, i.e., menstrual pain and 32 individuals " $15.9 \%$ " had no pain. The severity of menstrual pain in 63 individuals "31.3\%" was mild, in 90 individuals " $44.8 \%$ ", it was moderate and in 48 individuals "76.6\%", it was severe. Length of menstruation in 22 individuals "10.9\%" was less than 5 days, in 154 individuals "76.6\%", it was 5 - 7 days and in 25 individuals "12.4\%" the length of menstruation was more than 7 days .Analyzing the second questionnaire indicated that based on ACOG criteria, in 29 individuals " $14.4 \%$ ", premenstrual syndrome symptoms did not exist and other 172 individuals "85.6\%" had premenstrual syndrome symptoms. Moreover, given the DSM-IV scale, in 73 individuals "36.3\%", premenstrual dysphoric disorder (PMDD) did exist, i.e., 128 individuals 
“63.7\%” have not experienced this disorder. Findings showed that almost all university students participated in this study had experienced at least one moderate to severe symptom. The frequency and prevalence of symptoms are represented in Table 1.

Investigating the prevalence of every single symptoms of premenstrual syndrome indicated that, among university students under study, the most common mood symptom (emotional) was fatigue and lethargy "72.6\%" and the least common mood symptom was persistent anger or personal clashes "21.9\%". Moreover, among somatic symptoms (physical), abdominal pain was the most frequent symptom and gaining weight was the least frequent somatic symptom " $17.4 \%$ ".

Comparing mood symptoms (emotional) and somatic symptoms (physical) demonstrated that premenstrual syndrome was associated with mood changes "54.37\%" and somatic changes "45.63\%". According to ACOG criteria, among 173 individuals "85.6\%" who had PMS symptoms, severity of symptoms in 14 individuals "7\%" was severe, in 86 individuals " $42.8 \%$ ", it was moderate and in 72 individuals " $35.8 \%$ " it was mild.

However, considering the DSM-IV criteria, which is stricter and more restricted, among 73 individuals “36.3\%” with PMDD, 12 individuals "6\%" had severe symptoms, 47 individuals "23.3\%" had experienced moderate symptoms, and 14 individuals "7\%" had mild PMDD symptoms. The results obtained from comparing these two criteria, i.e., ACOG and DSM-IV, are depicted in Figure 1.

According to the diagram and indicated percentages, premenstrual dysphoric disorder was less common compared to premenstrual syndrome. The age distribution of university students indicated that age group of 21 -

Table 1. Prevalence (\%) of each symptom PMS.

\begin{tabular}{|c|c|c|c|}
\hline Frequency (percent) & Somatic symptoms (physical) & Frequency (percent) & Symptoms of affective (mood) \\
\hline 111 “55.3\%” & Joint and muscle pain & 100 “49.7\%” & Anxiety \\
\hline 67 “33.4\%” & Frequent urination & 130 “64.7\%” & Mood variability \\
\hline 35 “17.4\%” & Increased weight & 64 “31.9\%” & Stable Anger and personal involvement \\
\hline 131 “65.2\%” & Lower back pain & 52 “25.9\%” & Depressed mood \\
\hline 79 “39.3\%” & Acne & 60 “29.9\%” & Sense of immersion or outside the control \\
\hline 65 “32.4\%” & Nausea & 108 “53.7\%” & Change in appetite (overeating or anorexia) \\
\hline 86 “42.8\%” & Flatulence & 97 “47.8\%” & Difficulty in sleeping \\
\hline 72 “35.8\%” & Pain or tenderness of the breasts & 97 “47. 8\%” & Difficulty concentrating \\
\hline 126 “62.7\%” & Abdominal pain & 146 “72.6\%” & Fatigue and lethargy \\
\hline 66 “32.9\%” & Headache & 81 “41.3\%” & $\begin{array}{l}\text { Decreased interest in social relationships } \\
\text { and work }\end{array}$ \\
\hline
\end{tabular}

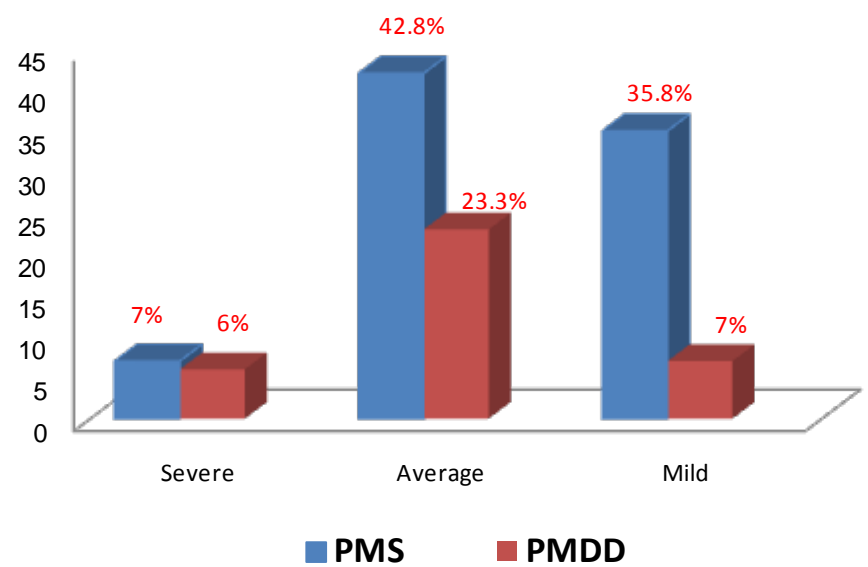

Figure 1. Comparison of different severity of symptoms caused by PMS and PMDD. 
23 years, i.e., 93 individuals “46.3\%” had the highest frequency, most of whom were single "82.6\%" and were non-indigenous " $82.6 \%$ " and their menstrual pain was moderate, 90 individuals " $44.8 \%$ ", and length of their menstruation was 5 - 7 days, 154 individuals "76.6\%". To examine the correlation of premenstrual syndrome with different age groups, marital status, place of residence, history of pregnancy, and menstrual status (dysmenorrhea, pain severity and length of menstruation), demographic variables were investigated using chi-square, ANOVA, and one-way regression analysis. The results indicated that the difference among premenstrual syndrome and dysmenorrhea and pain severity was only significant $(\mathrm{p}<0.05)$, i.e., among 169 individuals "84.1\%" suffered from dysmenorrhea, 149 individuals " $88.2 \%$ " had symptoms of this syndrome. Moreover, with increasing the pain severity from mild to severe, the prevalence of the syndrome increased that is from 48 individuals with severe pain, 45 individuals " $93.8 \%$ " demonstrated the symptoms.

Table 2 indicates the relationship between demographic characteristics of university students with PMS showing the difference between the significance of these two groups.

\section{Discussion}

In the current study, the prevalence of premenstrual syndrome in university students living in dormitories of Sistan and Baluchestan University was determined applying universal criteria. Previously conducted studies have estimated that up to 80 percent of women suffer from various degrees (at least one symptom) of premenstrual syndrome in their childbearing age. Using more restricted criteria like PMDD, the prevalence of these disorders reduced significantly and reached "4.9\% - 35.5\%" [24] [25].

In this study, the prevalence of this syndrome in the age group of 18 - 24 years was 172 individuals " $85.6 \%$ " and according to the ACOG criteria, its symptoms severity, i.e., mild, moderate and severe, was " $42.8 \%$ ", "35.8\%", and "7\%", respectively. This is consistent with the study of Bakr, et al. carried out on 396 students in Egypt indicating that in the age group of 18 - 24 years "89\%" individuals had experienced various degrees of this

\begin{tabular}{|c|c|c|c|c|}
\hline p value & PMS is not & PMS & Range & Variable \\
\hline \multirow[t]{3}{*}{$0 / 593$} & 14 “7\%” & 72 “35.8\%” & $18-20$ & \multirow[t]{3}{*}{ Age (years) } \\
\hline & 12 “6\%” & 81 “40.3\%” & $20-23$ & \\
\hline & 3 “1.5\%” & 19 “9.5\%” & More than 24 & \\
\hline \multirow[t]{2}{*}{ 0/979 } & 24 “11.9\%” & 142 “75.6\%” & Single & \multirow[t]{2}{*}{ Marital Status } \\
\hline & 5 “2.5\%” & 30 “14”9\%” & Married & \\
\hline \multirow[t]{2}{*}{$0 / 304$} & 7 “3.5\%” & 28 “13.9\%” & Native & \multirow[t]{2}{*}{ Status of residence } \\
\hline & 22 “10.9\%” & 144 “71.6\%” & Expatriates & \\
\hline \multirow[t]{2}{*}{ 0/991 } & 1 “0/5\%” & 6 “3\%” & There & \multirow[t]{2}{*}{ Pregnancy status } \\
\hline & 28 “13.9\%” & 166 “82.6\%” & Not & \\
\hline \multirow[t]{2}{*}{ 0/016* } & 20 “10\%” & 149 “74.1\%” & There & \multirow[t]{2}{*}{ Dysmenorrhea } \\
\hline & 9 “4.5\%” & 23 “11.4\%” & Not & \\
\hline \multirow[t]{3}{*}{$0 / 001^{*}$} & 18 “9\%” & 45 “22.4\%” & Low & \multirow[t]{3}{*}{ Pain } \\
\hline & 8 “4\%” & 82 “40.8\%” & The average & \\
\hline & 3 “1.5\%” & 45 “22.4\%” & Extreme & \\
\hline \multirow[t]{3}{*}{$0 / 858$} & 4 “2\%” & 18 “9\%” & Less than 5 days & \multirow[t]{3}{*}{ During menstruation } \\
\hline & 21 “10.4\%” & 133 “66.2\%” & 7-5 Days & \\
\hline & 4 “2\%” & 21 “10.4\%” & More than 7 days & \\
\hline
\end{tabular}

*Significance. 
syndrome [35].

Adiguzel, et al. conducted a study on 541 women aged 15 - 49 years old in Turkey. This study indicated that the prevalence of premenstrual syndrome was "72.2\%" and its severe type was "6.1\%" [36]. In Tehran, Aghazadeh, et al. reported that the prevalence of premenstrual syndrome was "60\%", among which $64 \%$ indicated mild symptoms, "32\%" demonstrated moderate symptoms, and 3\% had severe symptoms [37].

Previous studies emphasized on the significant relationship between menstruation pain and premenstrual syndrome [38].

Also in our study, the correlation was significant for dysmenorrhea (similar pain intensity), but according to Table 2 there was no significant relationship between age, pregnancy, marital status, place of residence, and length of menstruation.

In a study carried out in Jima University in Ethiopia and Thailand, depression and having appetite for specific foods were the most reported changes [39].

In the current study, based on the frequencies listed in Table 1, among psychological symptoms (emotional), fatigue and lethargy, mood changes, changes in appetite had the highest prevalence and among somatic symptoms (physical), abdominal pain, back pain, joints and muscle pain had the highest frequencies. Moreover, in this study, due to its extremely restricted criteria, the percentage of premenstrual dysphoric disorder dropped and reached "36.3\%".

In an investigation conducted by Antai carried out on 200 Nigerian students in Calabar University, the results indicated that the prevalence of PMS in students aged 16 - 31 was "85.5\%" and the most common symptoms in the group under study were muscle pain, acne, chest pain, puffy face, depression and distress, respectively [40]. In another study, 18 - 24 years old participants reported at least one symptom of PMS. Somatic symptoms like abdominal pain, tiredness, acne, muscle pain, abdominal bloating, headache, diarrhea, constipation, weight gain and emotional symptoms like mood changes, anger, depression, distress, and sensitivity were reported. In terms of behavioral changes, change in appetite, poor concentration, and sleep disorders were reported [35]. Therefore, although the results of conducted studies in various countries have a lot in common, there is still debate whether the most significant changes relate to psychological changes or somatic ones. In a study examining the relationship between women's beliefs about the prevalence of PMS and the occurring changes, the findings indicated that many women have misperceptions about this concept such that they mostly exaggerate about what they have really experienced. This is rooted in their culture and traditions [41].

Differences between the prevalence and various symptoms of this syndrome in different studies may be due to cultural differences, assessment tools, reported symptoms, type of study, method of selecting the population, and/or that some of the participants may not honestly explain their problems and that a number of researchers do not consider some of the symptoms as signs for diagnosing this syndrome [42].

\section{Conclusion}

Limited number of conducted studies in this area, inability of measuring symptoms directly and application of retrospective and self-reported data which can lead to some memory errors in the recorded data can be mentioned as the limitations of the current study. In general, given the results of the present study, as many other national and international studies emphasized, the high prevalence of premenstrual syndrome in university students can be mentioned. Therefore, holding workshops, adding a chapter to some courses (like family planning) to raise students' general information about physiology of menstruation and the relationship between hormonal changes and symptoms and also applying preventive strategies, using proper non-interventional treatment to help creating adjustment and improving the quality of life, health and well-being of young adult girls and eventually wives, mothers and families are highly recommended. Given that in the present era many women are involved in social, occupational, educational, familial issues and other responsibilities, if one may not find a solution for these individuals, the community will suffer from its many complications. Since there is no permanent cure for premenstrual syndrome, methods for prevention or reduction of symptoms are the best ways to deal with this syndrome; therefore, further research in this area seems essential.

\section{Acknowledgements}

This study was conducted in dormitories in the University of Sistan and Baluchestan. We sincerely thanked all students who helped us to accomplish this study. 


\section{References}

[1] Taylor, D. (2005) Primenstrual Symptoms and Syndromes Guidelines for Symptom Management and Self Care. Journal of Obstetrics \& Gynaecology, 5, 228-41.

[2] Azhary, S., Karimi Chatrudi, A., Attarzadeh, R. and Mazloom, R. (2005) Officacy of Group Aerobic Exercise Program on the Intensity of Premenstrual Syndrome. The Iranian Journal of Obstetrics, Gynecology and Infertility, 8, 119-28. [In Persian].

[3] Clarke, A. (1985) Premenstrual Syndrome: Single or Multiple Causes? Canadian Journal of Psychiatry, 30, 474-482.

[4] Speroff, L. and Fritz, M.A. (2004) Clinical Gynecologic Endocrinology and Infertility. 7th Edition, Lippincott Williams \& Wilkins, Baltimore, 547-571.

[5] Berkowitz, R.S., Barbieri, R.L., Dunaif, A.E., Kistner, R.W. and Ryan, K.J. (1999) Principle and Practice. 7th Edition, Mosby, Philadelphia, 392-395.

[6] William, R. and Keye Jr. (2004) Premenstrual Syndrome (PMS). Encyclopedia of Endocrine Diseases, 49, 73.

[7] Yonkers, K.A., O’Brien, P.M. and Eriksson, E. (2008) Premenstrual Syndrome. Lancet, 371, 1200-1210. http://dx.doi.org/10.1016/S0140-6736(08)60527-9

[8] Hillard, P.A., Berek, J.S. and Novak, E. (2002) Novak’s Gyncology. Lippincott Williams \& Wilkins, New York, 13.

[9] Baker, F.C., Colrain, I.M. and Trinder, J. (2008) Reduced Parasympathetic Activity during Sleep in the Symptomatic Phase of Severe Premenstrual Syndrome. Journal of Psychosomatic Research, 65, 13-22. http://dx.doi.org/10.1016/j.jpsychores.2008.04.008

[10] Georgantopoulou, C. and Field, S. (2009) Treatment of Premenstrual Syndrome with the Desogestrcl-Only Pill (Cerazette) in an Adolescent Girl. Journal of Pediatric \& Adolescent Gynecology, 22, e1-e3. http://dx.doi.org/10.1016/j.jpag.2008.04.009

[11] Petta, C.A., Osis, M.J., de Padua, K.S., Bahamondes, L. and Makuch, M.Y. (2010) Premenstrual Syndrome as Reported by Brazilian Women. International Journal of Gynecology \& Obstetrics, 108, 40-43. http://dx.doi.org/10.1016/j.ijgo.2009.07.041

[12] Silva, C.M., Gigante, D.P., Carret, M.L. and Fassa, A.G. (2006) Population Study of Premenstrual Syndrome. Revista de Saúde Pública, 40, 47-56. http://dx.doi.org/10.1590/S0034-89102006000100009

[13] Mustaniemi, S., Sipola-Leppänen, M., Hovi, P., Halbreich, U., Vääräsmäki, V., Räikkönen, K., Pesonen, A., Heinonen, K., et al. (2011) Premenstrual Symptoms in Young Adults Born Preterm at Very Low Birth Weight-From the Helsinki Study of Very Low Birth Weight Adults. BMC Women's Health, 10, 11-25.

[14] Pray, W.S. (1998) Premenstrual Syndrome. American Family Physician, 50, 1309-1317.

[15] Dickerson, L.M., Mazyck, P.J. and Hunter, M.H. (2003) Hunter Premenstrual Syndrome. American Family Physician, 67, 1743-1752.

[16] Violetta, S., Agnieszka, D., Krzysztof, N. and Ryszard, P. (2010) The Complexity of Premenstrual Dysphoric Disorder-Risk Factors in the Population of Polish Women. Reproductive Biology and Endocrinology, 14, 8-14.

[17] Forrester-Knauss, C., Zemp Stutz, E., Weiss, C. and Tschudin, S. (2011) The Interrelation between Premenstrual Syndrome and Major Depression: Results from a Population-Based Sample. BMC Public Health, 12, 795. http://dx.doi.org/10.1186/1471-2458-11-795

[18] Paula, K. and Braverman, M.D. (2007) Premenstrual Syndrome and Premenstrual Dysphoric Disorder. Journal of Pediatric and Adolescent Gynecology, 20, 3-12. http://dx.doi.org/10.1016/j.jpag.2006.10.007

[19] Milewicz, A. and Jedrzejuk, D. (2006) Premenstrual Syndrome: From Etiology to Treatment. International Symposium on Phytomedicines in Gynecology, 55, s47-s54.

[20] Steiner, M. and Pearlstein, T. (2000) Premenstrual Dysphoria and the Serotonin System: Pathophysiology and Treatment. Journal of Clinical Psychiatry, 61, 17-21.

[21] Nisar, N., Zehra, N., Haider, G., Munir, A.A. and Sohoo, N.A. (2008) Frequency, Intensity and Impact of Premenstrual Syndrome in Medical Students. Journal of College of Physicians and Surgeons Pakistan, 18, 481-484.

[22] American Psychiatric Association (1994) Diagnostic \& Statistical Manual of Mental Disorders. APA, Washington DC, 714-718.

[23] Henshaw, C.A. (2007) PMS: Diagnosis, Aetiology, Assessment and Management: Revisiting Premenstrual Syndrome. Advances in Psychiatric Treatment, 13, 139-146. http://dx.doi.org/10.1192/apt.bp.106.003392

[24] Bakhshani, N.M., Mousavi, M.N. and Khodabandeh, G. (2009) Prevalence and Severity of Premenstrual Symptoms among Iranian Female University Students. Journal of Pakistan Medical Association, 59, 205-208.

[25] Wittchen, H.U., Becker, E., Lieb, R. and Krause, P. (2002) Prevalence, Incidence and Stability of Premenstrual Dys- 
phoric Disorder in the Community. Psychological Medicine, 32, 119-132. http://dx.doi.org/10.1017/S0033291701004925

[26] Freeman, E.W. (2003) Premenstrual Syndrome and Premenstrual Dysphoric Disorder: Definitions and Diagnosis. Psychoneuroendocrinology, 28, 25-37. http://dx.doi.org/10.1016/S0306-4530(03)00099-4

[27] Dadvar, R., Dadvar, F. and Fathabadi, M.H. (2011) The Impact of Premenstrual Syndrome on Social Participation of the 25-35 Year Old Female Staffs of Baft City (Kerman Province) in 2010. Journal of American Science, 7, $324-328$. (In Persian)

[28] Lee, J.C., Yu, B.K., Byeon, J.H., Lee, K.-H., Min, J.H. and Park, S.H. (2011) A Study on the Menstruation of Korean Adolescent Girls in Seoul. Korean Journal of Pediatrics, 54, 201-206. http://dx.doi.org/10.3345/kjp.2011.54.5.201

[29] Bertone, J. (2009) Vitamin D and the Occurrence of Depression: Causal Association or Circumstantial Evidence? Nutrition Reviews, 67, 481-492. http://dx.doi.org/10.1111/j.1753-4887.2009.00220.x

[30] Rizk, D., Mosallam, M., Alyan, S. and Nagelkerke, N. (2006) Prevalence and Impact of Premenstrual Syndrome in Adolescent Schoolgirls in the United Arab Emirates. Acta Obstetricia et Gynecologica Scandinavica, 85, 589-598. http://dx.doi.org/10.1080/00016340600556049

[31] Rivlin, M.E. and Martin, R.W. (1999) Manual of Clinical Problems in Obstetrics and Gynecology. 4th Edition, Little Brown and Company, Boston, New York, Toronto, London, 73-74.

[32] Yonkers, K.A., O’Brien, P.M. and Eriksson, E. (2008) Premenstrual Syndrome. The Lancet, 371, 1200-1210. http://dx.doi.org/10.1016/S0140-6736(08)60527-9

[33] Vichnin, M., Freeman, E.W., Lin, H., Hillman, J. and Bui, S. (2006) Premenstrual Syndrome (PMS) in Adolescents: Severity and Impairment. Journal of Pediatric and Adolescent Gynecology, 19, 397-402. http://dx.doi.org/10.1016/j.jpag.2006.06.015

[34] Ahmadi, M. (2004) The Effect of Hypericum Perforutum on Premenstrual Syndrome in Student Girls in Tehran University of Medical Sciences in 2004. Master's Dissertation, Tehran University of Medical Sciences, Tehran. (In Persian)

[35] Bakr, I.S. and Ezz-Elarab, H. (2010) Prevalence of Premenstrual Syndrome and the Effect of Its Severity on the Quality of Life among Medical Student. The Egyptian Journal of Community Medicine, 28, 18-23.

[36] Adiguzel, H., Taskin, E.O. and Danaci, A.E. (2007) The Symptomatology and Prevalence of Symptoms of Premenstrual Syndrome in Manisa, Turkey. Turkish Journal of Psychiatry, 18, 215-222.

[37] Aghazadeh Naeini, A., Tamjidi, A. and Vallaei, N. (1996) Epidemiologic Study of Premenstrual Syndrome in 15-45 Years Old Women in Tehran during the Year 1995. Pejouhandeh, 1, 53-61. (In Persian)

[38] Da Silva, C.M.L., Gigante, D.P. and Minten, G.C. (2008) Premenstrual Symptoms and Syndrome According to Age at Menarche in a 1982 Birth Cohort in Southern Brazil. Cadernos de Saúde Pública, 24, 835-844. http://dx.doi.org/10.1590/S0102-311X2008000400014

[39] Thu, M., Diaz, E.O.G. and Sawhsarkapaw (2006) Premenstrual Syndrome among Female University Students in Thailand. AU Journal of Technology, 9, 158-162.

[40] Antai, A., Udezi, A., Ekanem, E., Okon, U. and Umoiyoho, A. (2004) Premenstrual Syndrome Prevalence in Students of the University of Calabar, Nigeria. African Journal of Biomedical Research, 7, 45-50.

[41] Gonda, X., Telek, T., Juhász, G., Lazary, J., Vargha, A. and Bagdy, G. (2008) Patterns of Mood Changes throughout the Reproductive Cycle in Healthy Women without Premenstrual Dysphoric Disorders. Progress in Neuro-Psychopharmacology and Biological Psychiatry, 32, 1782-1788.

[42] Fritz, M.A. and Speroff, L. (2011) Clinical Gynecologic Endocrinology and Infertilityed. Lippincott Williams and Wilkins, Philadelphia, 8. 
Scientific Research Publishing (SCIRP) is one of the largest Open Access journal publishers. It is currently publishing more than 200 open access, online, peer-reviewed journals covering a wide range of academic disciplines. SCIRP serves the worldwide academic communities and contributes to the progress and application of science with its publication.

Other selected journals from SCIRP are listed as below. Submit your manuscript to us via either submit@scirp.org or Online Submission Portal.
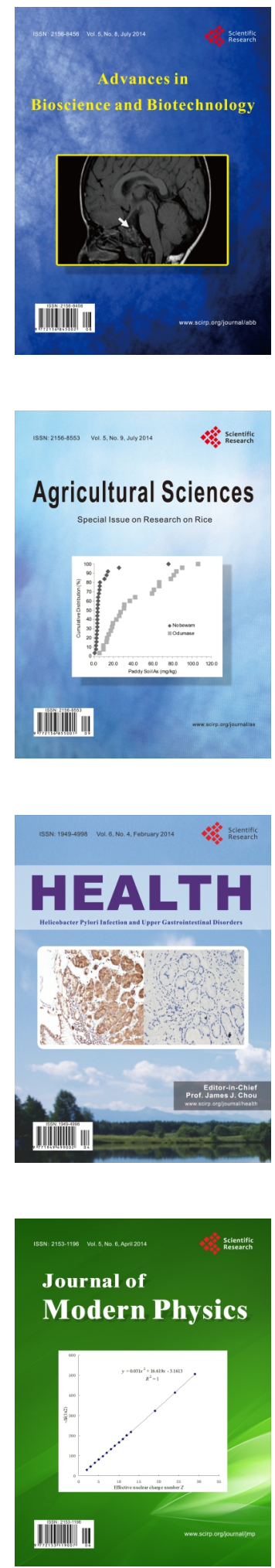
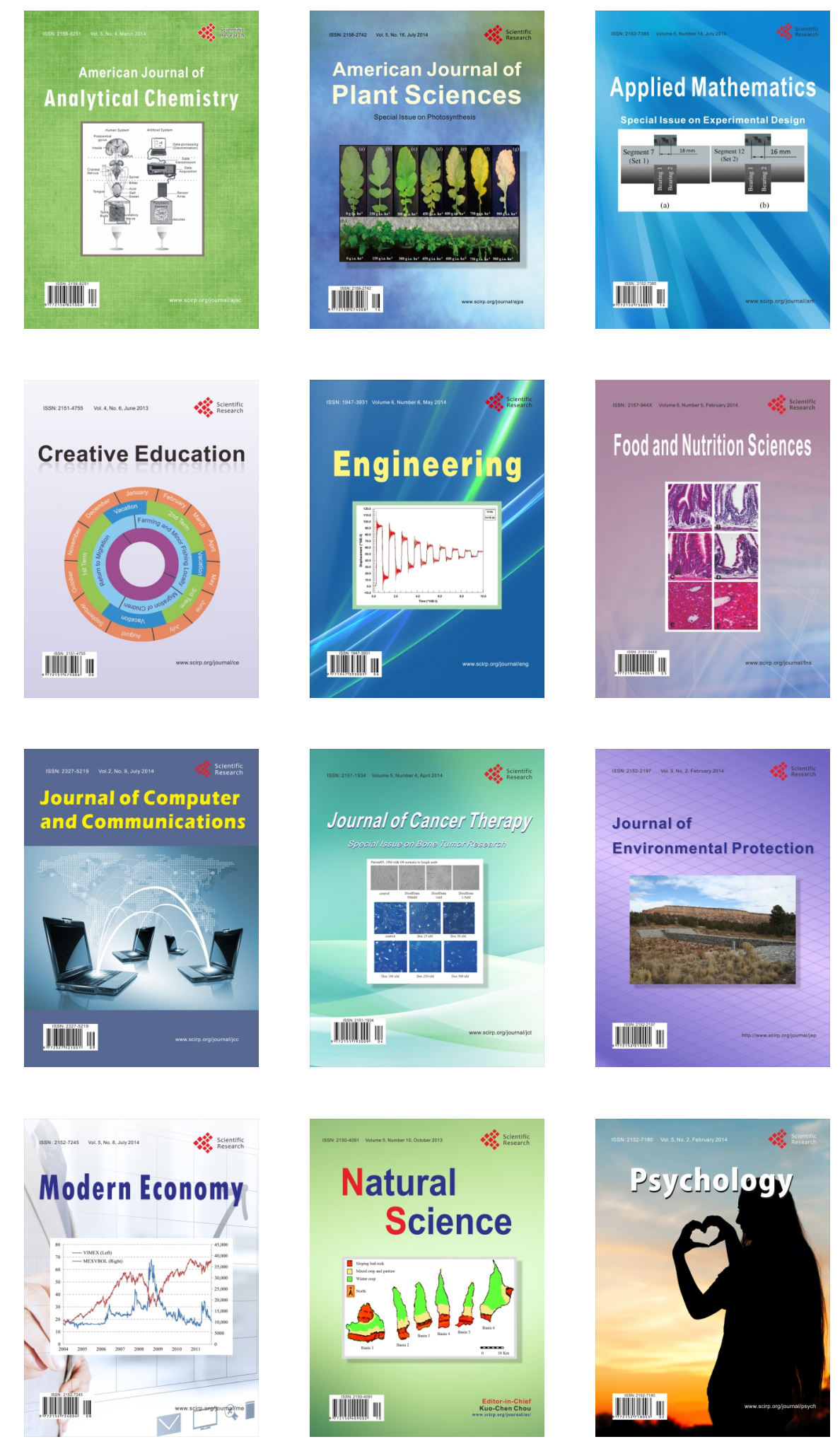